\title{
Study on the Necessity and Feasibility of Supervisor Professionalization
}

\author{
Xiaoshi Zhou \& Yu Zou \\ Economy and Management School, Shenyang Ligong University \\ Shenyang 110168, China \\ E-mail: jml_sit@163.com
}

\begin{abstract}
The original intention of supervisor professionalization which is an opinion in this article is to find a more effective supervisor system which can ensure the independent status of supervisors. First, in this article, we gave a consensual definition to the supervisor professionalization, and expatiated on the necessity of supervisor professionalization, and made feasibility analysis from four aspects including "separation of property and superintendence", "management of the special industry", "combination of supervisor professionalization and corporate governance system" and "the personnel market of professional supervisor", and finally obtained the general conclusions according to analysis results.
\end{abstract}

Keywords: Supervisor, Professionalization, Corporate governance, Independent director, Principal-agent, Feasibility

Because of information asymmetry, the agent must go with the supervision, which is one of basic opinions of the "principal-agent theory". Without supervision, the governance mechanism is not perfect, and if the function of supervision can not achieve acquired requirements, the mechanism is not perfect too. Supervisors are the main supervision personnel in the corporate government and management, and the key point which decides whether the supervision is effective is whether supervisors have independent status. We put forward that the formation of the independent status of supervisors should be improved by supervisor professionalization. So we need to discuss two problems, and one is the necessity of supervisor professionalization, and the other is the feasibility of supervisor professionalization.

\section{Meanings of supervisor professionalization}

The modern enterprise system is the outcome that the market economy develops sufficiently, and its prominent characteristic is the separation of the property and the management right, so a problem, how to supervise, must occur. The present governance mechanism gives part of the function to the board of directors, and gives part of the function to the board of supervisors.

In the artificial person governance mode of American company, the supervision function is performed by the board of directors, and there is no board of supervisors in the company, but the independent exterior director is acquired in the board of directors, whose main function is to supervise. The board of directors has the internal auditing committee which leads the internal auditing institution, and the internal auditing institution is composed by professional registered internal auditors. The internal audition institution completes the supervision works about the internal control in the company under the lead of the internal auditing committee. At the same time, the company accepts the supervision from the exterior auditing (social auditing). The characteristic of this supervision system is the professionalization, i.e. the main execution personnel of the supervision works including registered accountant in social audit and the registered internal auditor in internal audit are all professional personnel. In the Germanic company governance mode, the board of supervisors not only exists, but many regulations and laws such as the "Germanic Company Governance Principle" definitely regulate the composing, institution, acting principles and other contents of the board of supervisors (Wang, 2007, P.22). Japanese company also sets the board of supervisors which performs the independent discipline and is the necessary permanent body of the company, and the board of supervisors possesses definitely operation superintendence, financial superintendence, company representation right (in special instance) in the "Commercial Law" (Zhao, 2008, P.153).

In fact, Chinese active Company Law has given the frame of modern enterprise system which is a sort of governance structure, i.e. it confirms the statuses of the general meeting of shareholders, the board of directors, the board of supervisors and the management layer. The board of directors has two rights, and the first one is the decision-making right of important proceeding and the right of important project constitution, and the second one is the decision right of management institution and main personnel. The responsibility of the board of supervisors is mainly to perform the superintendence. The board of directors is responsible for the general meeting of shareholders, and the responsible object of the board of supervisors is not definite. Form the generation and election process of supervisors, the board of 
supervisors, but it always is limited by the board of directors in practice, i.e. the so-called phenomenon of "insider control" (Chen, 2004, P.92). Because there are always regulations about the figure of director in the memorandum of association, so the decision-making right and the superintendence of the board of directors can be inherited naturally, but the board of supervisors has not this characteristic. Whether for directors or supervisors, they all represent the shareholders to govern the company, and their rights all contain the component of "consignation".

For the limited liability company, its board of supervisors is always composed by "stakeholders". In recent years, for the joint stock limited partnership, the requirement that arranges non-stakeholders into the board of supervisors is more and more intensive. For many middle and small shareholders in the joint stock limited partnership, the information asymmetry exists between the decision-making and management layer and them, so they need the supervisors with more independent status to be responsible for them to supervise the decision-making and management, which is why Chinese Securities Regulatory Commission requires that the listed company sets independent director.

Whether for the limited liability company or the joint stock limited partnership, the relationships among the board of directors, the board of supervisors and the management layer is the base of the governance mechanism, and one of these relationships is the supervision relationship.

According to the principal-agent theory, the supervision is the necessary condition to realize the consignation, and the range of the supervision is consistent with the range of agent. Generally, the supervisors' supervision aims at the management layer, but for the company with numerous shareholders, most of them can not join the board of directors, so the decision of the board of directors should be supervised, which equals the consignation relationship between the general meeting of shareholders and the board of directors has been formed objectively, so the supervision should also be possessed. So the supervision should be independent not only from the management layer, but from the board of directors (Tang, 2004, P.179). In addition, the personnel who assume the supervision responsibility should have necessary knowledge and ability, or else, they can not achieve the requirement of the supervision.

The independence and technical requirements are the main reason to put forward the supervisor professionalization. But what is the supervisor professionalization?

The supervisor professionalization is that the supervisors of the company is composed by professional practicing personnel, and the supervision institution and supervision personnel should accept the operation lead of the corresponding profession organization and follow the constitutions and rules of the profession organization. That is to say, the supervisor professionalization should turn the supervisors' work into their occupation, and supervisors have to acquire the professional practicing certificate firstly and be the professional supervisors. One of premises of the professionalization is to establish corresponding profession organization (such as the registered supervisors association). Its aim is to make the supervision institution and supervisors' status more independent, and make the supervisor's work more professional, which are also the standards of the supervisor professionalization.

\section{Necessity of supervisor professionalization}

For the necessity of supervisor professionalization, we put forward following opinions in the article.

First, the supervisor professionalization can quicken forming the independent status of supervisors or supervision institution.

Second, the supervisor professionalization is propitious to enhance the professional level of supervision, and the professionalization will certainly help to enhance the quality of the supervision.

Third, the supervisor professionalization is propitious to perfect the modern enterprise system. Some problems occurred in the case of American "Enron Company" and some Chinese domestic listed companies have reflect the imperfection of the company supervision system from one side, and that also requires the supervisors' (or independent director) status should be more independent, and the practicing personal credit system should be more perfect. The supervisor professionalization is the effective approach to achieve these requirements.

Fourth, the supervisor professionalization is propitious to the harmony of the supervision functions. According to the feasibility analysis in the latter of the article, the industrial management mode after supervisor professionalization can harmonize and unify the supervisors' work and the operation of internal audit and avoid the crossed phenomena, which is very necessary objectively.

Fifth, the supervisor professionalization is propitious to the reform of state-owned enterprises. One of difficulties of the reform of state-owned enterprises is that separation of government functions from enterprise management is not thorough. The separation is the breaking of the management relationship and the staff relation. And the supervision chain should not be broken, but it should be strengthened (Hu, 2004, P.187). Because of the weakness of the supervision chain, the government always hesitates in "unlocking" and "control", and always confuses the staff relation chain and the supervision chain, so the result is that the supervision is not professional and independent, and the 
separation of government functions from enterprise management is very difficult.

\section{Feasibility of the separation of property and superintendence}

The core of modern property right theory is the description about the relationships between the property and various rights derived from it. The base supporting this theory is the separation of the property and the management right. In fact, the property and the superintendence could also be separated, but the separation must go with following conditions.

First, the separation of the property and the management right and the principle-agent relation of the management right exist. With the separation of the property and the management right, the management changes from independent mode to the dependent mode, so the necessity of supervision is needed.

Second, the object and contents of supervision should be definite. If the supervisors are responsible for the board of directors, the object of supervision is the management layer, and if the supervisors are responsible for the shareholders (the general meeting of shareholders or the shareholder representation meeting), the object of supervision includes not only the management layer but the board of directors. As the object of supervision is definite, the contents of supervision should also be definite, so the base of the separation of supervision function occurs.

Third, the superintendence has the object of consignation. The object can be or not be professional supervisors, but whether it is or not, there should be the system limitation to the superintendence.

To be brief, the condition of separation is that the premise of supervision exists, and the object and contents of supervision are definite, and the consigned environment exists.

When above conditions are possessed, the property and the superintendence can be separated. First, this separation has same base with the separation of the property and the management right, i.e. it accords with the hypothesis condition of the principle-agent theory. Second, the consigned supervision operation can exist independently, and can realize the equity of right and responsibility. Third, this separation accords with the social development rule of the refined social work division.

In the separation conditions, the consigned environment is the factor which needs to be further perfected, but it can not ultimately limit the separation, and other conditions have been possessed, so the separation of the property and the superintendence is possible.

\section{Combination of the supervisor professionalization and the company governance system}

The organic combination of the supervisor professionalization and the company governance system directly influences the feasibility of professionalization, which relates to the reform of the company system in fact, i.e. it relates to the redistribution of the supervisions on the governance layer and the management layer, the change of the supervision responsibility system, and the harmony among the decision-making right, the management right and the supervision right.

The separation of the property and the supervision right induces two changes, and the first one is the supervision right is performed by the supervision agent, and it is not the "natural heritance" any longer, and the other one is that the agent should be responsible for the consigner. This change of the responsibility system obviously is clearer than the line of "natural heritance".

The redistribution of the supervision right and the change of the responsibility system supplement each other. If supervisors are responsible for the board of directors, the supervision function of the board of directors should relegate to professional supervisors. And if supervisors are responsible for shareholders, the supervisors' decision supervision function should be correspondingly added. At the same time, the organizational institution should correspondingly confirm the management right and responsibility. But which mode we adopt, the redistribution of the superintendence can be confirmed.

When introducing the system of professional supervisor, one important problem is that the change of authority will reduce the running efficiency of the institution, for example, the right and responsibility don't match, the programs are too complex, and the power is abused, and the efficiency is lower. The intention to introduce the system of professional supervisor is to add the independence of the supervisor's work, and it will not change the decision and the management responsibility system. Generally, supervisors only have the checking right and reporting right, and they have not the decision right for the decision-making and management, so their rights will not limit the running of the decision and management. However, the reporting work may influence the decision and management programs and make the programs more complex, but this complexity will not have largely negative influences. First, the work occurs in the reporting process, and it will not interfere with the decision and management process. Second, by the more precise programs, supervisors can find the problems in the decision-making and management in time, which will make the later decision-making and management more scientific and reasonable. 


\section{Management of the special industry}

One of the running conditions of the professional system is the professional management of the occupation, and the intention of the management is to standardize the practicing behaviors and enhance the practicing skills. Whether the industrial management can guarantee the implementation of the professional system is decided by the guarantee functions of the system, the mechanism and the authority.

We can first use the industrial management system of accountant for references. The accountants are managed by the Accountant Association which is managed, instructed and supervised by the financial department of the government. Because the management has the legal proof (Law of the People's Republic of China on Certified Accountants), so the management has the character of authority. The management system mainly includes the regulations of the association about the practicing behaviors, the work criterions of the association, and the laws and regulations of the government to the industrial management.

Whether does the supervisor professionalization possess thus industrial management conditions? As viewed from the system, the government manages the association which manages practicing personnel, and this mode of industrial management is proved to be feasible and effective by the practice. So it is mature and feasible to establish the professional supervisor association which can connect the management of the government to the industry. And if the function of management is confirmed by laws (laws or regulations), the authority of the management can be confirmed. The problem is that who will be the administrative department. If the industrial and commercial department and the audit department of the government assume this function, both the disadvantages and the disadvantages will exist. The industrial and commercial department is the law-enforcing department of the "Company Law", and it follow a rational line to do the supervisor management work well, but it will encounter difficulties in the operation training and instruction. The function of the audit department is supervision which accords with supervisors' function, so it is a sort of reasonable arrangement to combine the internal auditor with supervisors and develop corresponding industrial management, but the audit industry emphasizes the auditing of the financial income and expenses, and the supervision work will be too narrow.

In individual opinion, it is fit to let the audit department as the administrative department of the industry. First, the close operations is more convenient for the practicing management, and especially audit department can absorb the standards and practices from international internal auditor association, extend the auditing supervision to the risk management and internal control, which can make the auditing and the supervisor's operation more compatible, and make the industrial management more easily base the operation management. Second, the internal auditor association is the industrial management organization which has existed, and it can fulfill the industrial management condition of supervisor professionalization only by proper adjustment.

\section{The personnel market of professional supervisor}

The professionalization means the special occupation skill will become the commodity, and the supply and demand of the professional personnel will be adjusted by the market. Which people can be the professional supervisors? This is the problem about the standard which is generated by the combination of certain criterion and shareholders' wills. Only if these two factors are definite or they are easy to be definite, the standard can be confirmed. To ensure the supply and demand of the talents and the realization of the talents' value, the standard must embody the character of the special industry.

The confirmation of the talents includes the works on two layers. The first layer is the admittance standard of the professional supervisor. The second layer is the marking of the ability grade for professional supervisor, such as the confirmation of the elementary-class talent, the confirmation of the middle-class talent and the confirmation of the super-class talent. The admittance standard mainly includes the longevity, the knowledge level and other evaluation contents, and the rating standard also includes the performance, occupational credit and other evaluation contents. These standards may be immature in the initial stage of the professionalization, especially for the actual operation, so the standard will influence the professionalization to some extent, but the influence will only be in some phases.

Another condition of talent commercialization is the price tag. Though the price of talents is generated in the supply and demand process to large extent, but because of the particularity of the professional supervisor market, the talent price will be an important node to run the supervisor personal market. If the market instruction prices of the talents with different classes can not be formed, it will be induce that the prices deviate from the values only depending on the relation of supply and demand, which not only make practicing personnel could not pull their weights, but increase the burden of the enterprise. The talent pricing (such as the instruction price) is a technical problem, it must need certain time to gradually reduce the difference of price and value.

In addition, the manager of this market should be the industrial management organization. If the professional supervisors are brought into common personal market to realize the supply and demand, the talent rating and talent price tag will hardly achieve the requirement of the industrial management. Furthermore, the salary and payment system 
of professional supervisor is special in the payment mode and payment channel, and the direct salary and payment system may influence the credit of the occupation (Guo, 2004, P.24). These characteristics indicate that the industrial association should serve as the manager of this market, and the market management mode and the association management mode are different, i.e. the body of the market is the professional supervisor and consigner, and for the salary and payment, the engagement and rating, simple administrative method can not be adopted.

Though above particularities exist in this market, but the personnel market of professional supervisor still has many common characteristics with general personnel market, and these particularities will not ultimately restrict the supervisor professionalization.

\section{Conclusions}

Through above analysis, the supervisor professionalization is propitious to enhance supervisors' practicing ability, cultivate occupational credit, fully implement the modern enterprise system, and enhance the independent status of supervisors more importantly. From the feasibility analysis of four aspects such as the separation of property and superintendence, the supervisor professionalization is basically feasible, and the disadvantage is that the immaturity of some stages may exist, but the disadvantage will be gradually cleared up in the professionalization process as the price will finally return to the balance point of supply and demand.

\section{References}

Chen, Zeya. (2004). What We Should Depend on to Manage the Managers. Enterprise Management. No.1. P.92.

Guo, Jing et al. (2004). Study on the Establishment of the Indirect Salary Payment System of Independent Director. Management Review. No.2. P.24.

$\mathrm{Hu}$, Hanxiang et al. (2004). The Property Right System Innovation of State Listed Company and the Perfection of Company Governance Structure. Enterprise Economy. No.2. P.187.

Tang, Decai et al. (2004). Analysis of the Implementation Actuality of Chinese Independent Director System. Enterprise Economy. No.2. P.179.

Wang, Shiquan. (2007). Headstream Review of Germany System of Board of Supervisors and Its Innovational Development. Securities Market Herald. No.6. P.22.

Zhao, Ping. (2008). Study on Japanese System of Board of Supervisors. Market Modernization. No.534. P.153. 